Bài báo khoa học

\title{
Thử nghiệm tích hợp mô hình Tank và Sóng động học một chiều để dự báo thủy văn hạn vừa trên lưu vực sông Ba
}

\author{
Bùi Văn Chanh ${ }^{1 *}$, Trần Ngọc Anh ${ }^{2,3}$, Nguyễn Quốc Huấn ${ }^{1}$, Nguyễn Thị Hoan ${ }^{1}$ \\ ${ }^{1}$ Đài Khí tượng Thủy văn khu vực Nam Trung Bộ, Tổng cục Khí tượng Thủy văn; \\ buivanchanh@gmail.com; huantvtp@gmail.com; hoannguyen.1311@gmail.com \\ ${ }^{2}$ Trung tâm Động lực học Thủy khí Môi Trường, Đại học Khoa học Tự nhiên, Đại học \\ Quốc gia Hà Nội; tranngocanh@hus.edu.vn \\ ${ }^{3}$ Khoa Khí tượng Thủy văn và Hải dương học, Đại học Khoa học Tự nhiên, Đại học Quốc \\ gia Hà Nội; tranngocanh@hus.edu.vn \\ * Tác giả liên hệ: buivanchanh @gmail.com; Tel.: +84-915620289
}

Ban Biên tập nhận bài: 01/11/2020; Ngày phản biện xong: 25/12/2020; Ngày đăng bài: $25 / 02 / 2021$

Tóm tắt: Mô hình Tank đã được ứng dụng trong thời gian dài, ở nhiều nơi trên thế giới và trở thành công cụ hữu hiệu trong nghiệp vụ dự báo hiện nay. Tuy nhiên, Tank là mô hình mưa dòng chảy thông số tập trung, không mô phỏng được quá trình truyền lũ và tập trung dòng chảy trên lưu vực nên mô phỏng còn hạn chế. Với các lưu vực nhỏ, mô hình Tank được đánh giá là sử dụng có hiệu quả cao vì quá trình tập trung và truyền dòng chảy ít ảnh hưởng đến diễn biến lưu lượng tại cửa ra. Ngoài ra, những tác động đáng kể của hồ chứa đến dòng chảy lưu vực cũng không được tính toán trong mô hình Tank nên chất lượng mô phỏng chưa cao. Để sử dụng mô hình Tank được cho lưu vực lớn và mô phỏng tác động của hồ chứa đến dòng chảy trong sông, nghiên cứu đã tích hợp mô hình Tank với mô hình Sóng động học một chiều phi tuyến và phương pháp diễn toán dòng chảy qua hồ Runge - Kutta bậc 3. Bộ mô hình tích hợp được ứng dụng thử nghiệm để dự báo thủy văn thời hạn 5 ngày trên lưu vực sông $\mathrm{Ba}$ cho kết quả mô phỏng và dự báo tốt hơn việc chỉ sử dụng mô hình Tank. Kết quả nghiên cứu đã xây dựng được công cụ dự báo thủy vắn hạn vừa tại trạm thủy văn Củng Sơn tại Đài Khí tượng Thủy văn khu vực Nam Trung Bộ bằng việc ứng dụng bộ mô hình trên.

Từ khóa: Mô hình Tank; Sóng động học; Lưu vực sông Ba.

\section{Mở đầu}

Mô hình Tank do Sugawara đề xuất và ứng dụng đầu tiên năm 1956 tại Trung tâm Quốc gia Phòng chống Lũ lụt Nhật Bản. Mô hình đã được sử dụng rộng rãi trên thế giới và trong nghiệp vụ dự báo tại hầu hết các cơ quan dự báo ở Việt Nam. Tuy nhiên, Tank là mô hình mưa dòng chảy thông số tập trung, đã trung bình hóa các đặc trưng tự nhiên của lưu vực nên không mô phỏng được quá trình tập trung dòng chảy, truyền sóng lũ , không mô phỏng chi tiết và tác động của công trình thủy lợi đến diễn biến dòng chảy lưu vực sông [1]. Do dó, trên các lưu vực vừa và lớn có mức độ thay đổi đáng kể về đặc trưng tự nhiên, việc ứng dụng đem lại kết quả mô phỏng chưa cao; lưu vực có ảnh hưởng lớn của hồ chứa có chất lượng mô phỏng kém và gần như không thể ứng dụng được mô hình. Để khắc phục các nhược điểm trên của mô hình Tank, nghiên cứu đã chia lưu vực lớn thành các tiểu lưu vực, chia lưu vực khống chế đến tuyến đập các hồ và coi như là một tiểu lưu vực. Dòng chảy qua hồ chứa được diễn toán bằng phương pháp Runge-Kutta bậc 3 . Đầu ra của mô hình Tank ở các tiểu lưu 
vực được kết nối với mô hình Sóng động học một chiều phi tuyến để diễn toán dòng chảy trong mạng lưới sông; tại các nút có hồ chứa mô hình Sóng động học sử dụng phương pháp Runge Kutta bậc 3 để diễn toán [2]. Đa số các con sông trên thế giới và ở Việt Nam có sự ảnh hưởng của hồ chứa đến dòng chảy [3], những tác động này làm giảm chất lượng mô phỏng và dự báo thủy văn nhưng chưa được mô phỏng trong các mô hình mưa dòng chảy thông số tập trung, trong đó có mô hình Tank. Do đó, mô phỏng tác động của hồ chứa trong các mô hình toán thủy văn là rất cần thiết. Dòng chảy qua hồ hiện nay được mô phỏng bằng một số mô hình Mike Basin, HEC ResSim, các phương pháp Runge-Kutta, Patapop, đồ thị, lập bảng và thử dần [4]. Tuy nhiên, tích hợp phương pháp Runge-Kutta bậc 3 trong mô hình Sóng động học là một hướng nghiên cứu mới để mô phỏng quá trình liên tục dòng chảy trong sông.

Để chủ động và triển khai có hiệu quả phương án phòng chống thiên tai, sản xuất đã đặt ra yêu cầu dự báo thời hạn vừa, trong đó dự báo thủy văn trong mùa lũ với thời hạn dự báo 5 ngày và mùa cạn là 10 ngày [5]. Đối với lưu vực sông $\mathrm{Ba}$, dự báo hạn vừa không chỉ có vai trò quan trong trong phòng chống thiên tai, sản xuất nông nghiệp, cung cấp nước cho sinh hoạt và công nghiệp mà còn phục vụ điều tiết hệ thống hồ chứa, sản xuất điện năng. Tuy nhiên, lưu vực sông Ba khá rộng lớn, đặc điểm tự nhiên và khí hậu thuy văn biến đổi lớn theo không gian, có hệ thống hồ chứa rất phức tạp nên công tác dự báo thủy văn hạn vừa gặp nhiều khó khăn. Công tác dự báo trên lưu vực sông $\mathrm{Ba}$ do nhiều đơn vị dự báo cấp tỉnh và khu vực thực hiện; trong đó, dự báo dòng chảy tại trạm thủy văn Củng Sơn do Đài Khí tượng Thủy văn tỉnh Phú Yên và Đài khu vực Nam Trung Bộ thực hiện, các trạm thượng lưu do Đài Khí tượng Thủy văn khu vực Tây Nguyên và các Đài tỉnh trực thuộc thực hiện. Việc thực hiện dự báo dòng chảy tại trạm Củng Sơn gặp rất nhiều khó khăn do đây là trạm đo lưu lượng cuối cùng trong hệ thống, chịu sự tác động phức tạp của dòng chảy lưu vực và hệ thống hồ chứa.

Công cụ dự báo hạn vừa hiện nay trên lưu vực sông Ba chủ yếu là phương pháp hồi quy, mô hình thống kê nên việc mô phỏng tác động của hồ chứa rất hạn chế. Ngoài ra, sự biến đổi phức tạp của dòng chảy trên lưu vực cũng như tác động của biến đổi khí hậu dẫn đến chất lượng dự báo chưa cao của các phương pháp và mô hình thống kê. Mặc dù, một số nghiên cứu đã sử dụng mô hình thủy văn thông số IFAS, MIKE NAM để dự báo dòng chảy thời hạn dài, tuy nhiên mới chỉ ứng dụng được cho mùa cạn, mô phỏng quá trình dòng chảy trong sông còn hạn chế [6]. Yêu cầu dự báo hạn vừa hiện nay cần thực hiện cho nhiều đặc trưng trung bình, lớn nhất, nhỏ nhất và thời gian xuất hiện, tuy nhiên việc dự báo cực trị và thời gian chưa thể thực hiện với các phương pháp và mô hình thống kê. Do đó, phương pháp sử dụng kết hợp mô hình Tank, Sóng động học một chiều và phương pháp Runge - Kutta bậc 3 khắc phục các nhược điểm của các phương pháp dự báo trên và là cơ sở để cải thiện chất lượng dự báo thời hạn vừa. Các mô hình sau khi cải tiến, tích hợp đã ứng dụng thử nghiệm cho lưu vực sông Ba đến trạm thủy văn Củng Sơn.

Nghiên cứu đã mô phỏng dòng chảy trên tiểu lưu vực hồ An Khê, Yaun Hạ, Krông Hnăng, Sông Ba Thượng, Ia Mlah, sông Hinh, gia nhập khu giữa đến hồ Sông Ba Hạ và trạm thủy văn Củng Sơn [7]. Dòng chảy của các tiểu lưu vực này được mô phỏng bằng mô hình Tank, các tiểu lưu vực các hồ được kết nối với Runge-Kutta bậc 3 để diễn toán qua hồ trước khi kết nối với mô hình Sóng động học một chiều phi tuyến cùng với dòng chảy khu giữa được mô phỏng bằng mô hình Tank. Dòng chảy qua hồ Sông $\mathrm{Ba} H a$ được diễn toán bằng Runge-Kutta bậc 3 với lưu lượng đầu vào từ mô hình Sóng động học và tiếp tục sử dụng mô hình này để mô phỏng dòng chảy đến trạm Củng Sơn, trị số mực nước của trạm này được khai toán từ bảng tra $\mathrm{Q}=\mathrm{f}(\mathrm{H})$ năm 2016.

\section{Phương pháp nghiên cứu}

\subsection{Giới thiệu về khu vực nghiên cưu}


Sông Ba là con sông lớn khu vực Miền trung và Tây nguyên, bắt nguồn từ độ cao khoảng $2000 \mathrm{~m}$ thuộc địa phẩn tỉnh Gia Lai. Sông chảy theo hướng bắc-nam và đổ ra biển tại thành phố Tuy Hòa tỉnh Phú Yên; có các nhánh sông Pơmơrê gia nhập tại huyện Phú Thiện tỉnh Gia Lai, sông Krông Hnăng gia nhập tại huyện M'drắk tỉnh Đắk Lắk, sông Hinh gia nhập tại huyện Sông Hình tỉnh Phú Yên. Trên lưu vực có các trạm chính gồm: trạm thủy văn An Khê, Pơmơrê, Ayunpa, Củng Sơn và Phú Lâm; trạm khí tượng An Khê, Ayunpa, M'drắk, Sơn Hòa, Tuy Hòa và 11 trạm đo mưa nhân dân. Trên lưu vực sông Ba có rất nhiểu hồ chứa, trong đó có các hồ chính thuộc quy trình vận hành liên hồ chứa gồm: An Khê, Ka Nắk, Ayun Hạ, Krông Hnăng, Ba Hạ. Số liệu các trạm khí tượng thủy văn từ năm 1977 đến nay, các trạm đo mưa tự động và hồ chứa đầy đủ có khoảng trong 5 năm gần đây. Để đảm bảo dữ liệu hiệu chỉnh và kiểm định, nghiên cứu sử dụng số liệu của 02 trận lũ năm 2016.

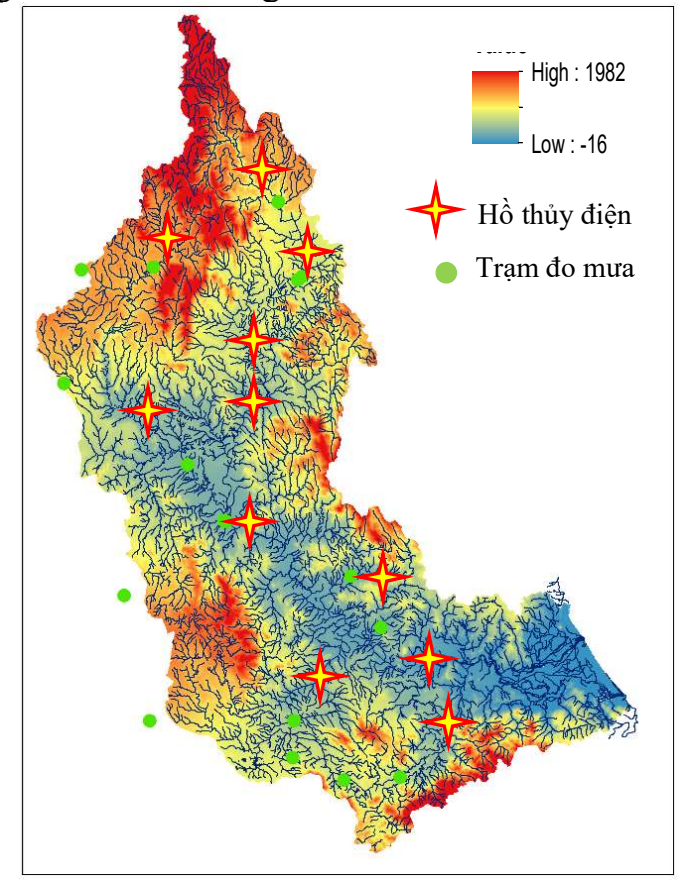

Hình 1. Bản đồ địa hình và sông suối lưu vực sông Ba.

\subsection{Co' sở lý thuyết mô hình Tank}

Bể chứa trên cùng được chia thành hai phần: trên và dưới, giữa chúng xảy ra sự trao đổi ẩm. Tốc độ truyền ẩm từ dưới lên $\left(\mathrm{T}_{1}\right)$ và từ trên xuống $\left(\mathrm{T}_{2}\right)$ được tính như sau:

$$
\mathrm{T}_{1}=\mathrm{TB}_{0}+(1-\mathrm{XA} / \mathrm{PS}) \times \mathrm{TB} \quad(1) \quad \mathrm{T}_{2}=\mathrm{TC}_{0}+(1-\mathrm{XS} / \mathrm{SS}) \times \mathrm{TC}
$$

Trong đó $\mathrm{XS}, \mathrm{SS}$ là lượng ẩm thực và lượng ẩm bão hòa phần dưới bể $\mathrm{A} ; \mathrm{TB}_{0}, \mathrm{~TB}, \mathrm{TC}_{0}$, TC là các thông số truyền ẩm.

Dòng chảy từ bể $\mathrm{A}$ :

Lượng ẩm đi vào bể $\mathrm{A}$ là mưa $(\mathrm{P})$, dòng chảy qua các cửa bên (YA1, YA2) và cửa đáy (YA0) được tính như sau:

$$
\begin{aligned}
& \mathrm{H}_{\mathrm{f}}=\mathrm{XA}+\mathrm{P}-\mathrm{PS} \\
& \mathrm{YA}_{1}=\left(\mathrm{H}_{\mathrm{f}}-\mathrm{HA}_{1}\right) \times \mathrm{A}_{1} \\
& \mathrm{YA}_{1}=0 \\
& \mathrm{YA}_{2}=\left(\mathrm{H}_{\mathrm{f}}-\mathrm{HA}_{2}\right) \times \mathrm{A}_{2}+\left(\mathrm{H}_{\mathrm{f}}-\mathrm{HA}_{3}\right) \times \mathrm{A}_{3} \\
& \text { YAo }=\mathrm{H}_{\mathrm{f}} \times \mathrm{A}_{0} \\
& \text { Khi } \mathrm{H}_{\mathrm{f}}>\mathrm{HA}_{1} \\
& \text { Khi } \mathrm{H}_{\mathrm{f}} \leq \mathrm{HA}_{1} \\
& \mathrm{YA}_{2}=\left(\mathrm{H}_{\mathrm{f}}-\mathrm{HA}_{2}\right) \times \mathrm{A}_{2} \\
& \text { Khi } \mathrm{H}_{\mathrm{f}}>\mathrm{HA}_{3} \\
& \mathrm{YA}_{2}=0 \\
& \text { Khi } \mathrm{H}_{\mathrm{f}}>\mathrm{HA}_{2} \\
& \text { Khi } \mathrm{H}_{\mathrm{f}} \leq \mathrm{HA}_{2}
\end{aligned}
$$

Dòng chảy từ các bể $\mathrm{B}, \mathrm{C}, \mathrm{D}$ : 


$$
\begin{array}{rlrl}
\mathrm{YB}_{0} & =\left(\mathrm{XB}+\mathrm{YA}_{0}\right) \times \mathrm{B}_{0} & \\
\mathrm{YB}_{1}=\left(\mathrm{XB}+\mathrm{YA}_{0}-\mathrm{HB}\right) \times \mathrm{B}_{1} & \mathrm{KhiXB}+\mathrm{YA}_{0}>\mathrm{HB} \\
\mathrm{YB}_{1}=0 & \mathrm{KhiXB}+\mathrm{YA}_{0} \leq \mathrm{HB} \\
\mathrm{YC}_{0}=\left(\mathrm{XC}+\mathrm{YB}_{0}\right) \times \mathrm{C}_{0} & \mathrm{KhiXC}+\mathrm{YB}_{0}>\mathrm{HC} \\
\mathrm{YC}_{1}=\left(\mathrm{XC}+\mathrm{YB}_{0}-\mathrm{HC}\right) \times \mathrm{C}_{1} & \mathrm{KhiXC}+\mathrm{YB}_{0} \leq \mathrm{HC}
\end{array}
$$

Dòng chảy từ bể $\mathrm{CH}$ :

$$
\begin{aligned}
& \mathrm{QCH}=\mathrm{YA}_{2}+\mathrm{YA}_{1}+\mathrm{YB}_{1}+\mathrm{YC}_{1}+\mathrm{YD}_{1} \\
& \mathrm{Y}=(\mathrm{XCH}+\mathrm{QCH}) \times \mathrm{CH}_{1}+(\mathrm{XCH}+\mathrm{QCH}-\mathrm{H}) \times \mathrm{CH}_{2} \quad \mathrm{Khi}(\mathrm{XCH}+\mathrm{QCH})>\mathrm{H} \\
& \mathrm{Y}=(\mathrm{XCH}+\mathrm{QCH}) \times \mathrm{CH} 1 \quad \mathrm{Khi}(\mathrm{XCH}+\mathrm{QCH}) \leq \mathrm{H} \\
& \mathrm{Q}=[(\mathrm{Y} \times \mathrm{F}) / \Delta \mathrm{t}] \times 10^{3}\left(\mathrm{~m}^{3} / \mathrm{s}\right)
\end{aligned}
$$

Trong đó $\mathrm{Q}$ là lưu lượng mặt cắt tại cửa ra lưu vực $\left(\mathrm{m}^{3} / \mathrm{s}\right) ; \mathrm{F}$ là diện tích lưu vực $\left(\mathrm{km}^{2}\right)$; $\Delta \mathrm{t}$ là thời gian tính toán $(\mathrm{s})$.

\subsection{Cơ sở lý thuyết mô hình Sóng động học}

Sóng động học tạo nên do sự thay đổi trong dòng chảy như thay đổi về lưu lượng nước hoặc tốc độ sóng là vận tốc truyền thay đổi dọc theo kênh dẫn. Tốc độ sóng phụ thuộc vào loại sóng đang xét và có thể hoàn toàn khác biệt với vận tốc dòng nước. Đối với sóng động học, các thành phần gia tốc và áp suất trong phương trình động lượng đã bị bỏ qua nên chuyển động của sóng được mô tả chủ yếu bằng phương trình liên tục. Do đó sóng đã mang tên sóng động học và động học nghiên cứu chuyển động trong đó không xét đến ảnh hưởng của khối lượng và lực. Mô hình sóng động học được xác định bằng các phương trình Saint Venant như sau [8]:

$$
\begin{array}{ll}
\text { - Phương trình liên tục: } & \frac{\partial Q}{\partial x}+\frac{\partial A}{\partial t}=q \\
\text { - Phương trình động lượng: } & \mathrm{S}_{\mathrm{o}}=\mathrm{S}_{\mathrm{f}} \\
& \mathrm{A}=\alpha \mathrm{Q} \beta
\end{array}
$$

Trong đó $\mathrm{A}$ là diện tích mặt cắt ướt; $\mathrm{Q}$ là lưu lượng; $\mathrm{q}$ là nhập lưu; $\mathrm{S}_{\mathrm{o}}$ là độ dốc sông; $\mathrm{S}_{\mathrm{f}}$ là độ dốc ma sát.

Áp dụng sơ đồ sai phân ẩn phương trình (16) thu được phương trình sai phân sóng động học phi tuyến.

$$
\frac{\Delta t}{\Delta x} Q_{i+1}^{j+1}+\alpha\left(Q_{i+1}^{j+1}\right)^{\beta}=\frac{\Delta t}{\Delta x} Q_{i}^{j+1}+\alpha\left(Q_{i+1}^{j}\right)^{\beta}+\Delta t\left(\frac{q_{i+1}^{j+1}+q_{i+1}^{j}}{2}\right)
$$

Đây là phương trình phi tuyến đối với $Q_{i+1}^{j+1}$ do đó cần được giải bằng phương pháp số, trong chương trình lập trình đã giải phương trình (19) bằng phương pháp lặp Newton [8]. Sử dụng kết quả tính toán từ mô hình Sóng động học một chiểu tuyến tính làm giá trị ban đầu của phép lặp Newton. Sơ đồ sử dụng phương trình (19) là một sơ đồ ổn định không điều kiện và có thể sử dụng các trị của $\Delta \mathrm{t} / \Delta \mathrm{x}$ trong một phạm vi khá rộng mà không tạo ra sai số lớn trong hình dạng của đường quá trình lưu lượng [9].

Mô hình Sóng động học một chiều phi tuyến cho một nhánh sông được xây dựng từ phương trình (19) và giải bằng phương pháp lặp Newton [8]. Mô hình này sử dụng mô hình Sóng động học một chiều Tuyến tính để làm điều kiện ban đầu giúp bài toán của mô hình Phi tuyến nhanh hội tụ, giảm bước lặp trong quá trình giải hệ phương trình Saint Venant. Áp dụng phương pháp phân cấp sông và mô hình Phi tuyến này để mô phòng dòng chảy cho một 
mạng lưới sông. Phương pháp phân cấp sông theo thứ tự như sau: sông chính có số thứ tự là 1 (sông cấp 1 ), sông đồ trực tiếp vào sông cấp 1 là sông cấp 2 (số thứ tự là 2 ), sông đổ trực tiếp vào sông cấp 2 là sông cấp 3 (thứ tự là 3 ), ... quá trình phân cấp sông như trên được tiếp tục cho đến cấp sông cuối cùng được đưa vào tính toán trong mô hình (hình 2) [10].

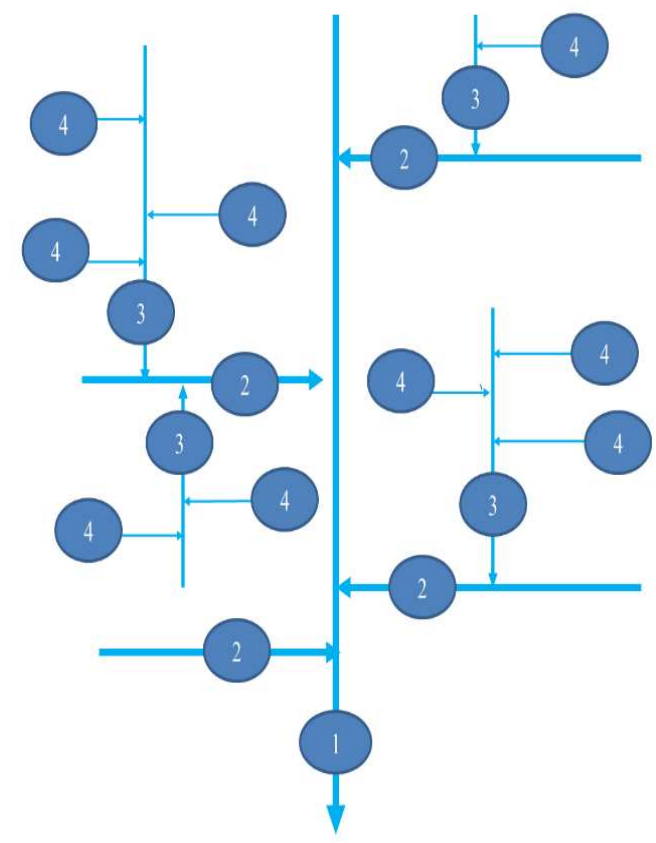

Hình 2. Sơ đồ phân cấp lưới sông.

\subsection{Co sở lý thuyết phwơng pháp Runge-Kutta bậc 3}

Theo sơ đồ Runge-Kutta bậc 3 , chia khoảng thời gian $\Delta \mathrm{t}$ thành 3 thời đoạn nhỏ và sẽ tính toán các giá trị liên tiếp của mực nước và lưu lượng cho mỗi đoạn thời gian.

Phương trình liên tục được biểu diễn bằng [9]:

$$
\frac{d S}{d t}=I(t)-Q(H)
$$

Trong đó $\mathrm{S}$ là dung tích hồ; $\mathrm{I}(\mathrm{t})$ là lưu lượng đi vào hồ như một hàm theo thời gian; $\mathrm{Q}(\mathrm{H})$ là lưu lượng dòng ra khỏi hồ được xác định bằng mực nước hoặc bằng cột nước.

Số gia về thể tích $\mathrm{dS}$ tương ứng với số gia của mực nước $\mathrm{dH}$ có thể được tính như sau :

$$
\mathrm{dS}=\mathrm{A}(\mathrm{H}) \times \mathrm{dH}
$$

Với $\mathrm{A}(\mathrm{H})$ là diện tích mặt nước hồ tại mực nước $\mathrm{H}$. Do đó, phương trình liên tục được việt như sau [8]:

$$
\frac{d H}{d t}=\frac{I(t)-Q(H)}{A(H)}
$$

Trong sơ đồ bậc 3 , mỗi khoảng thời gian $\Delta \mathrm{t}$ được chia thành 3 thời đoạn nhỏ và ứng với mỗi thay đổi $\mathrm{dH}$ cần phải tính được các số gia $\Delta \mathrm{H}_{1}, \Delta \mathrm{H}_{2}, \Delta \mathrm{H}_{3}$ cho mỗi thời đoạn.

Cách tính gần đúng của số gia $\Delta \mathrm{H}_{1}, \Delta \mathrm{H}_{2}, \Delta \mathrm{H}_{3}$ cho khoảng thời gian thứ $\mathrm{j}$. Độ dốc $\mathrm{dH} / \mathrm{dt}$ xấp xỉ bằng $\Delta \mathrm{H} / \Delta \mathrm{t}$ sẽ được ước lượng trước tiên tại $\left(\mathrm{H}_{\mathrm{j}}, \mathrm{t}_{\mathrm{j}}\right)$, sau đó tại $\left(\mathrm{H}_{\mathrm{j}}+\Delta \mathrm{H}_{1} / 3, \mathrm{t}_{\mathrm{j}}+\Delta \mathrm{t} / 3\right)$ và cuối cùng tại $\left(\mathrm{H}_{\mathrm{j}}+2 \Delta \mathrm{H}_{2} / 3, \mathrm{t}_{\mathrm{j}}+2 \Delta \mathrm{t} / 3\right)$.

Ta có phương trình $[8]$ :

$$
\Delta H_{1}=\frac{I\left(t_{j}\right)-Q\left(H_{j}\right)}{A\left(H_{j}\right)} \Delta t
$$

$$
\Delta H_{2}=\frac{I\left(t_{j}+\frac{\Delta t}{3}\right)-Q\left(H_{j}+\frac{\Delta H_{1}}{3}\right)}{A\left(H_{j}+\frac{\Delta H_{1}}{3}\right)} \Delta t
$$




$$
\Delta H_{3}=\frac{I\left(t_{j}+\frac{2 \Delta t}{3}\right)-Q\left(H_{j}+\frac{2 \Delta H_{2}}{3}\right)}{A\left(H_{j}+\frac{2 \Delta H_{2}}{3}\right)} \Delta t
$$

Giá trị $\mathrm{H}_{\mathrm{j}}+1$ được tính bằng:

$$
\mathrm{H}_{\mathrm{j}}+1=\mathrm{H}_{\mathrm{j}}+\Delta \mathrm{H}
$$

$$
\text { Trong đó: } \Delta H=\frac{\Delta H_{1}}{4}+\frac{3 \Delta H_{3}}{4}
$$

\subsection{Thiết lập mô hình Tank}

Mô hình Tank thiết lập cho các tiểu lưu vực trên lưu vực sông Ba gồm: hồ An Khê, Ayun Hạ, Krông Hnăng, Sông Ba Thượng, Ia Mlah, Sông Hinh và lượng gia nhập khu giữa. Trạm mưa được sử dụng trên lưu vực sông Ba gồm 11 trạm: KBang, An Khê, Pơmơrê, Chư Sê, Ayunpa, Eaknop, Mdrắk, Cà Lúi, Phú Thiện, Krôngpa, EaHleo. Số liệu sử dụng để hiệu chỉnh bộ thông số mô hình Tank từ ngày $30 / 10$ đến 11/11 năm 2016 (trận lũ 1 ) và kiểm định từ ngày $11 / 12$ đến 22/12 năm 2016 (trận lũ 2). Đánh giá chất lượng bằng chỉ tiêu Nash [11] của quá trình hiệu chỉnh bộ thông số mô hình Tank cho hồ An Khê đạt 0,84 , hồ Ayun Hạ đạt 0,86 , hồ Krông Hnăng đạt 0,85 ; quá trình kiểm định tại hồ An Khê đạt 0,85 , hồ Ayun Hạ đạt 0,87 , hồ Krông Hnăng đạt 0,80 .

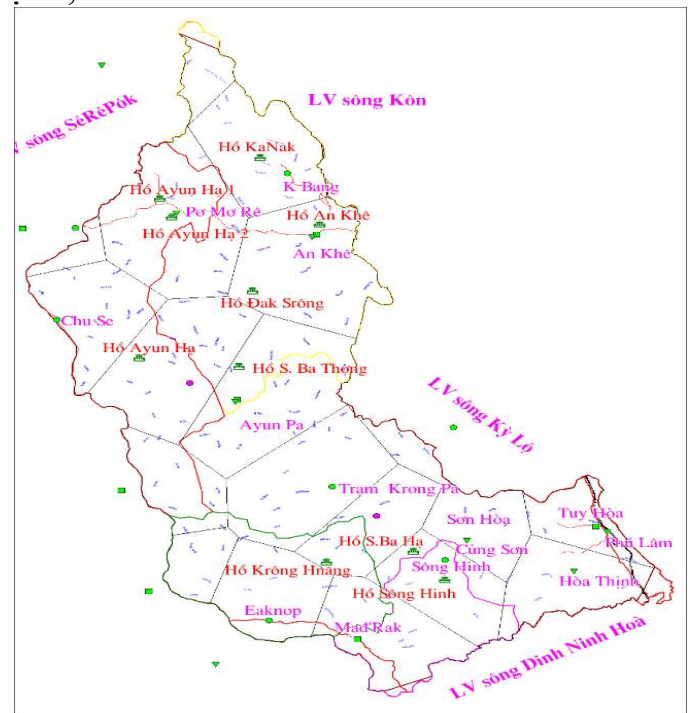

Hình 3. Bản đồ các tiểu lưu vực và đa giác các trạm mưa.

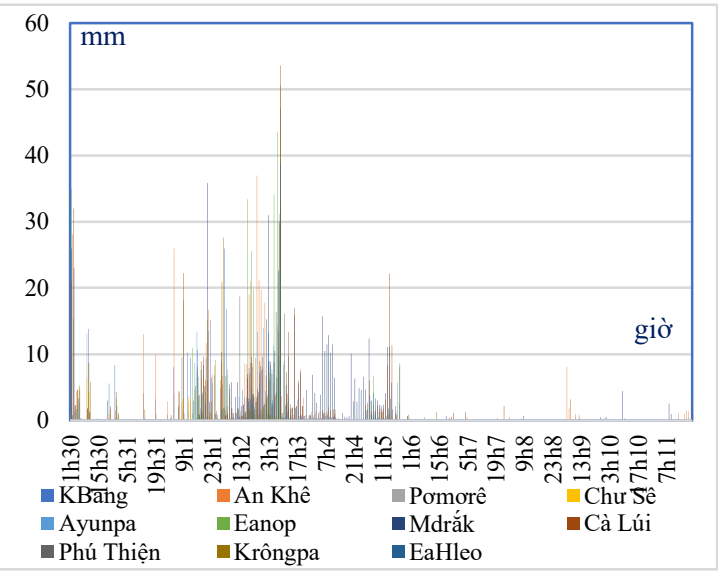

Hình 4. Biểu đồ mưa các trạm trận lũ 1 năm 2016.

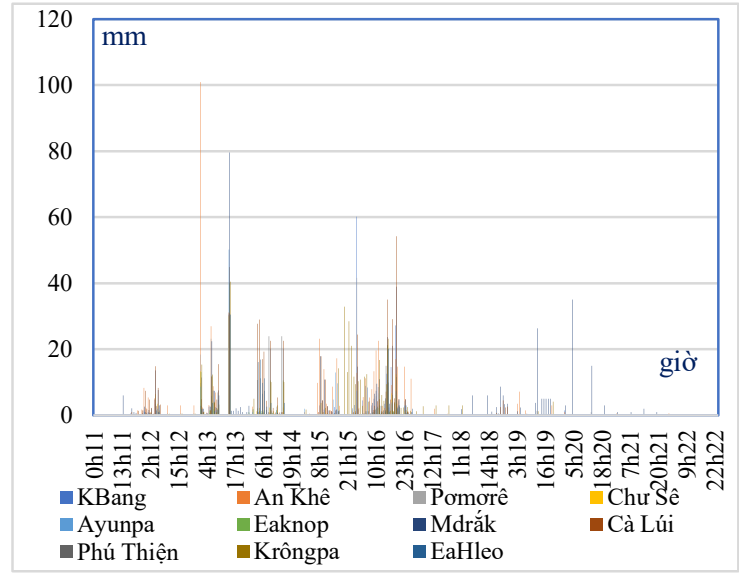

Hình 5. Biểu đồ mưa các trạm trận lũ 2 năm 2016. 


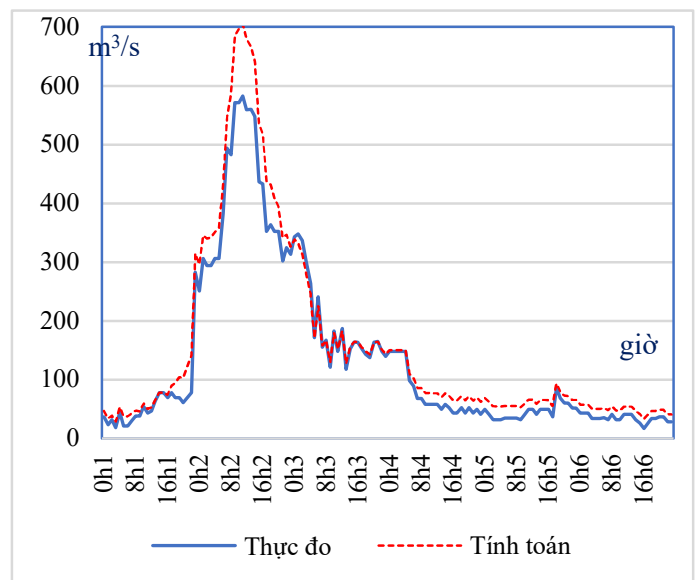

Hình 6. Hiệu chỉnh bộ thông số mô hình Tank lưu lượng về hồ An Khê.

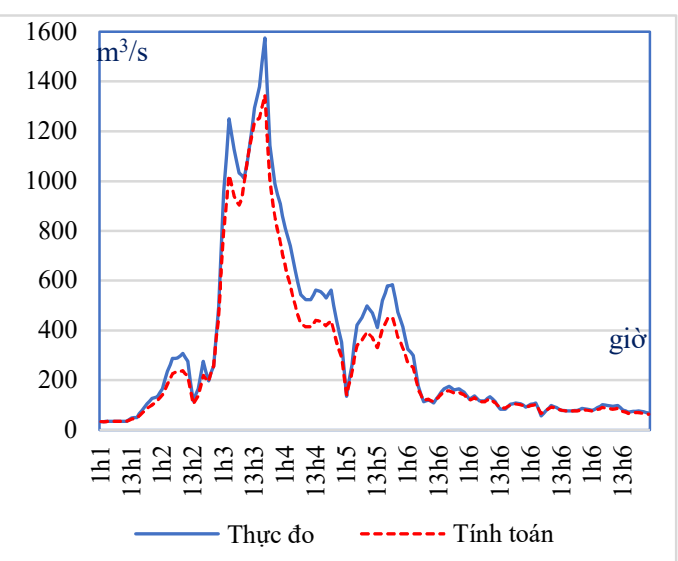

Hình 8. Hiệu chỉnh bộ thông số mô hình Tank lưu lượng về hồ Krông Hnăng.

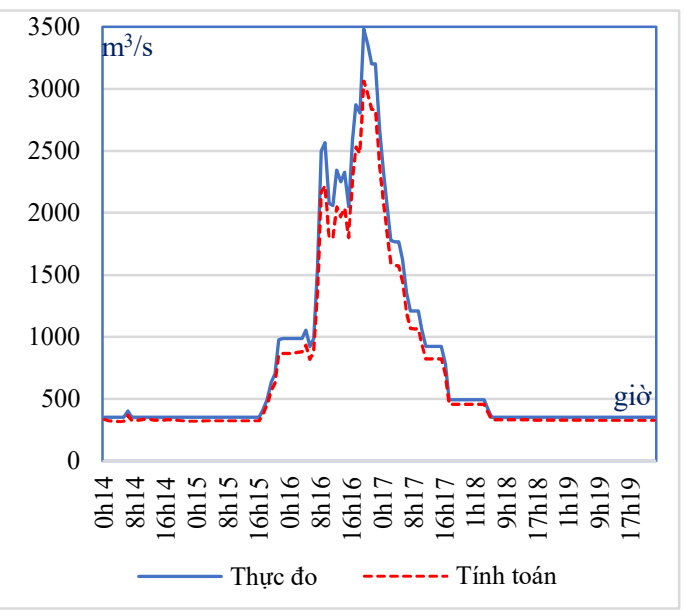

Hình 10. Kiểm định bộ thông số mô hình Tank lưu lượng về hồ Ayun Hạ.

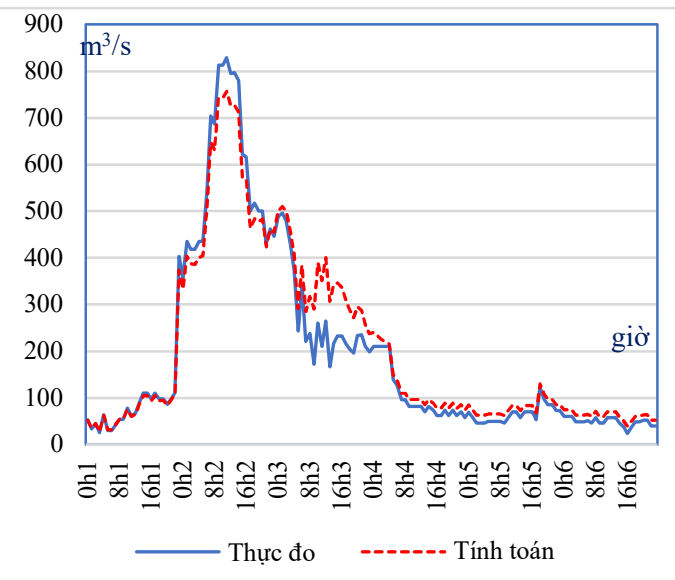

Hình 7. Hiệu chỉnh bộ thông số mô hình Tank lưu lượng về hồ Ayun Hạ.

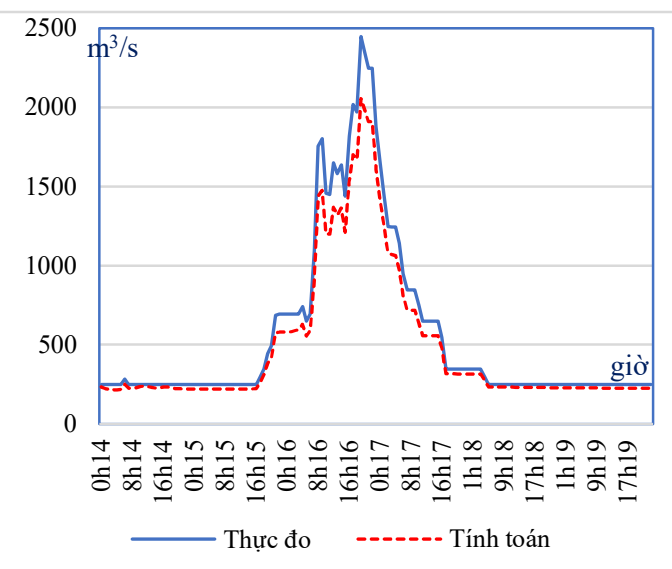

Hình 9. Kiểm định bộ thông số mô hình Tank lưu lượng về hồ An Khê.

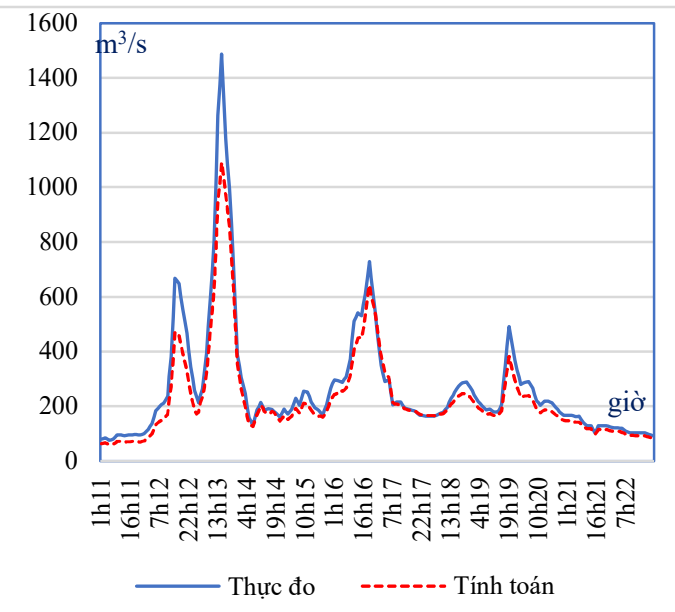

Hình 11. Kiểm định bộ thông số mô hình Tank lưu lượng về hồ Krông Hnăng. 


\subsection{Thiết lập diễn toán dòng chảy qua hồ bằng Runge-Kutta bậc 3}

Phương pháp diễn toán dòng chảy qua hồ Runge-Kutta bậc 3 được thiết lập dựa trên đường đặc tính lòng hồ (ZFV), mực nước ban đầu, các thông số của đập gồm: cao trình ngưỡng tràn, số cửa xả, chiều rộng một cửa xả. Trên lưu vực sông Ba có nhiều hồ chứa, trong nghiên cứu này sử dụng các hồ trong quy trình vận hành liên hồ chứa để mô phỏng gồm: An Khê, Ayun Hạ, Krông Hnăng, Sông Ba Hạ, Sông Ba Thượng, Ia Mlah, Sông Hinh [7].

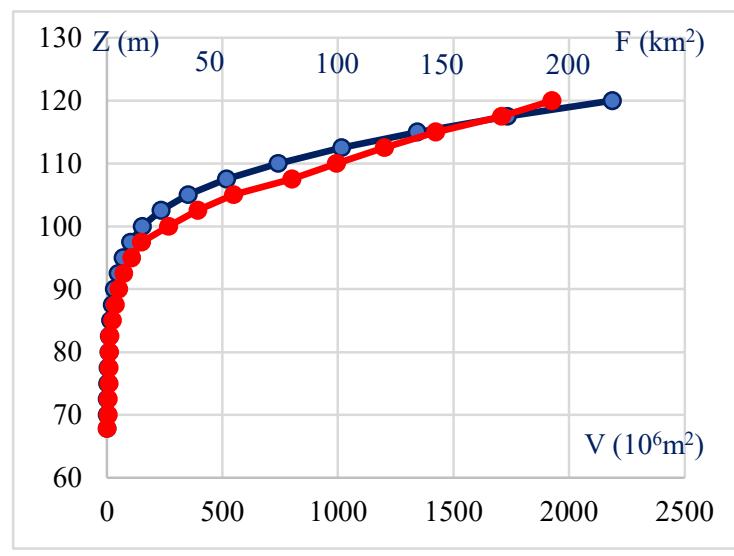

Hình 12. Đường đặc tính hồ Sông Ba Hạ.

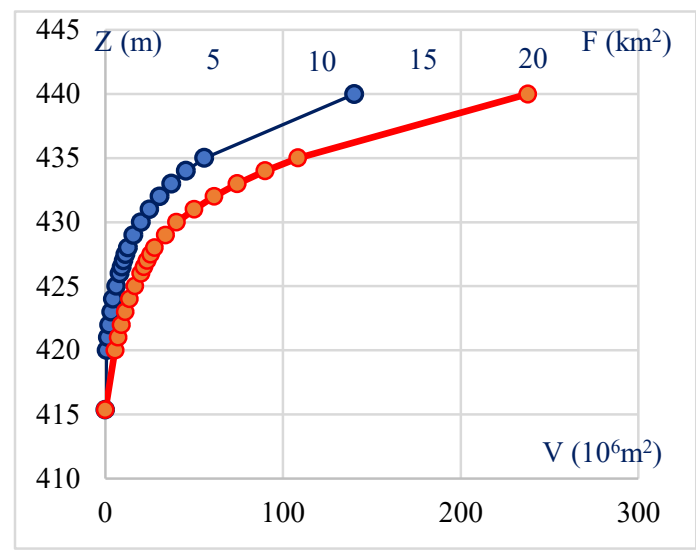

Hình 13. Đường đặc tính hồ An Khê.

\subsection{Thiết lập mô hình Sóng động học một chiều phi tuyến}

Mô hình Sóng động học một chiều Tuyến tính và Phi tuyến được thiết lập trên cơ sở mạng lưới thủy lực như đã phân cấp sông (hình 2). Nhánh sông gồm nhiều điểm nối với nhau được xác định bằng tọa độ, khoảng cách cộng dồn từ thượng lưu về hạ lưu. Tại mỗi điểm sông được tính toán độ dốc sông, hệ số nhám Manning (n), chiều rộng sông. Dữ liệu độ dốc sông được tính xấp xỉ với độ dốc địa hình dựa trên bản đồ DEM 90 [12], chiều rộng sông được đo trên ảnh viễn thám và kết hợp với bảng tra thủy lực [13] để xác định hệ số nhám Manning, từ hệ số nhám ban đầu của bảng tra, sau khi hiệu chỉnh và kiểm định đã xác định được hệ số nhám từ 0,031 đến 0,037 . Áp dụng sơ đồ phân cấp trên cho lưu vực sông Ba được thể hiện trong hình 14.

Đánh giá chất lượng mô phỏng theo chỉ tiêu Nash [11] mô hình Sóng động học một chiều phi tuyến cho quá trình hiệu chỉnh lưu lượng về hồ Sông $\mathrm{Ba} H a$ đạt 0,85 và tại trạm Củng Sơn đạt 0,87; quá trình kiểm định lưu lượng về hồ Sông $\mathrm{Ba} H a$ đạt 0,84 và tại trạm Củng Sơn đạ 0,86.

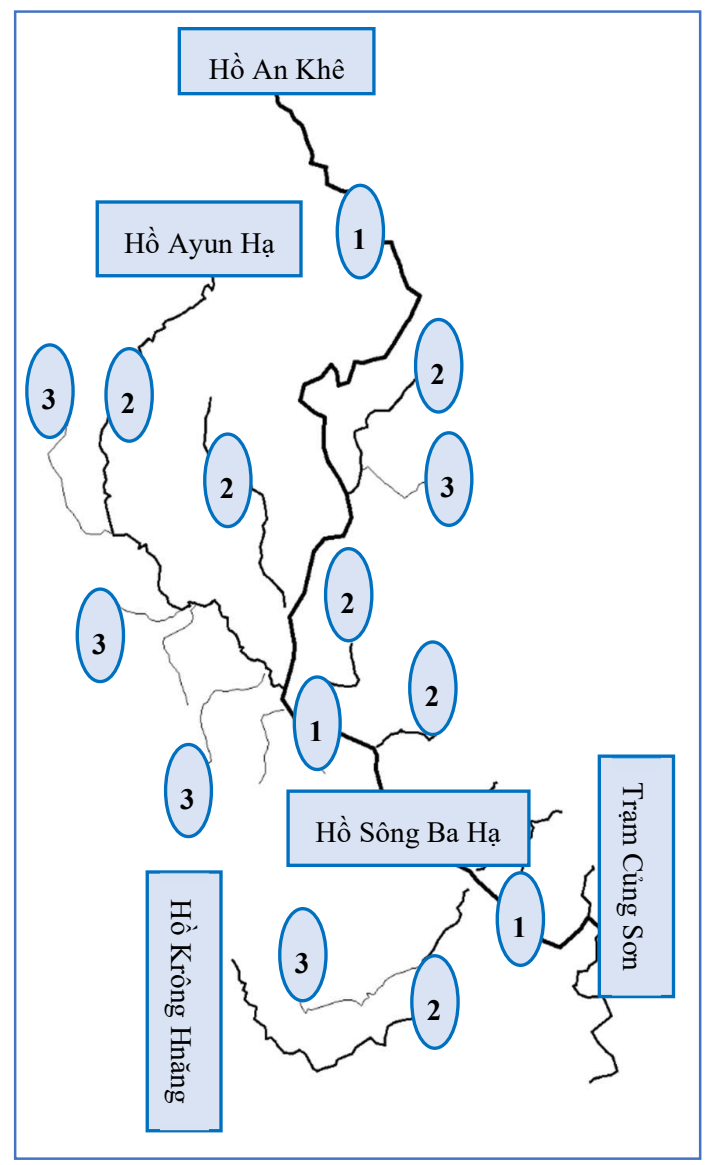

Hình 14. Phân cấp mạng lưới sông Ba. 


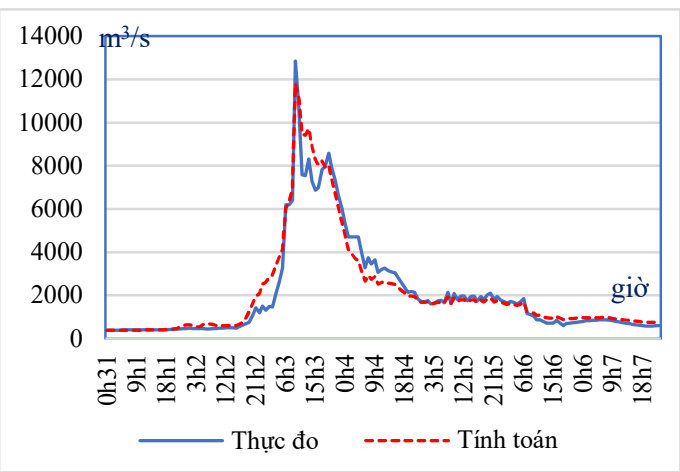

Hình 15. Kết quả hiệu chỉnh lưu lượng về hồ Sông $\mathrm{Ba}$ Hạ trận lũ 1 năm 2016.

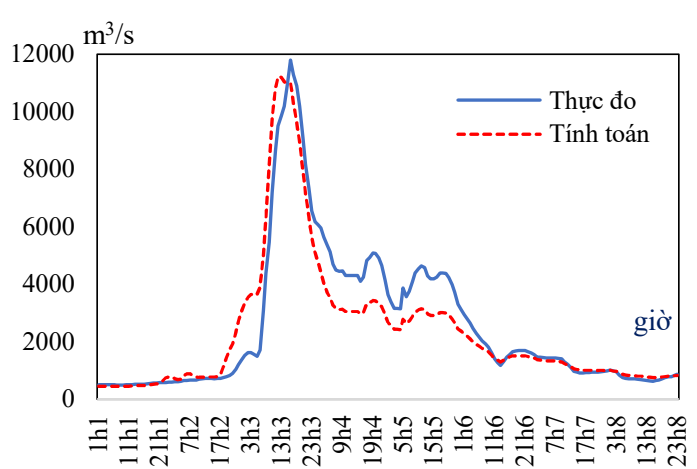

Hình 17. Kết quả hiệu chỉnh tại trạm Củng Sơn trận lũ 1 năm 2016.

\section{Kết quả và thảo luận}

Kết quả hiệu chỉnh và kiểm định bộ thông số mô hình Tank và Sóng động học một chiều phi tuyến được đánh giá đạt loại tốt bằng chỉ tiêu Nash, bộ mô hình tích hợp đủ điều kiện sử dụng trong nghiệp vụ dự báo thủy văn. Nghiên cứu đã thử nghiệm dự báo thời đoạn 5 ngày cho trạm thủy văn Củng Sơn từ ngày $1 / 9$ đến ngày 20 tháng 10 năm 2020. Số liệu mưa thực đo được khai thác từ 27 trạm đo mưa tự động, lượng mưa dự báo được trích xuất từ sản phẩm mô hình số trị WRF thời đoạn 1 giờ và độ phân giải $9 \mathrm{~km}$. Đánh giá chất lượng dự báo tại trạm thủy văn Củng Sơn đạt 85\% [14].

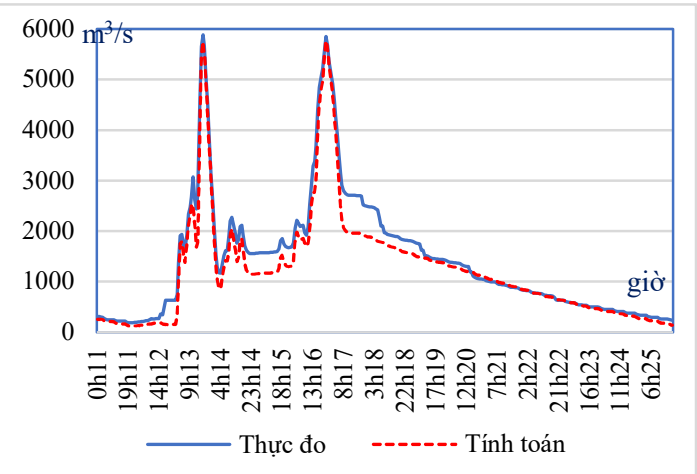

Hình 16. Kết quả kiểm định lưu lượng về hồ Sông Ba Hạ trận lũ 1 năm 2016.

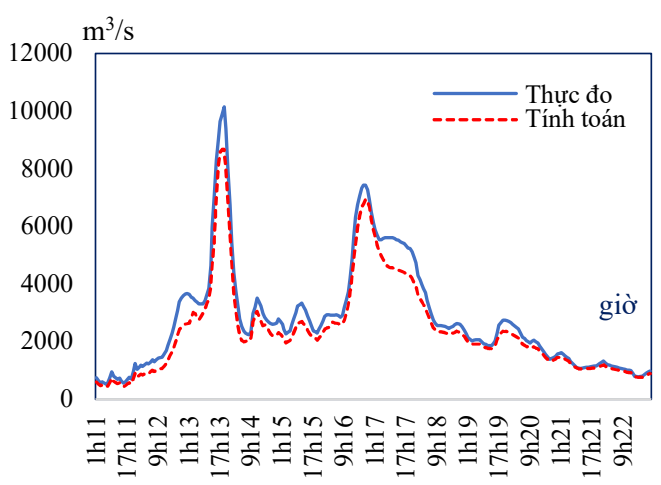

Hình 18. Kết quả kiểm định tại trạm Củng Sơn trận lũ 2 năm 2016.

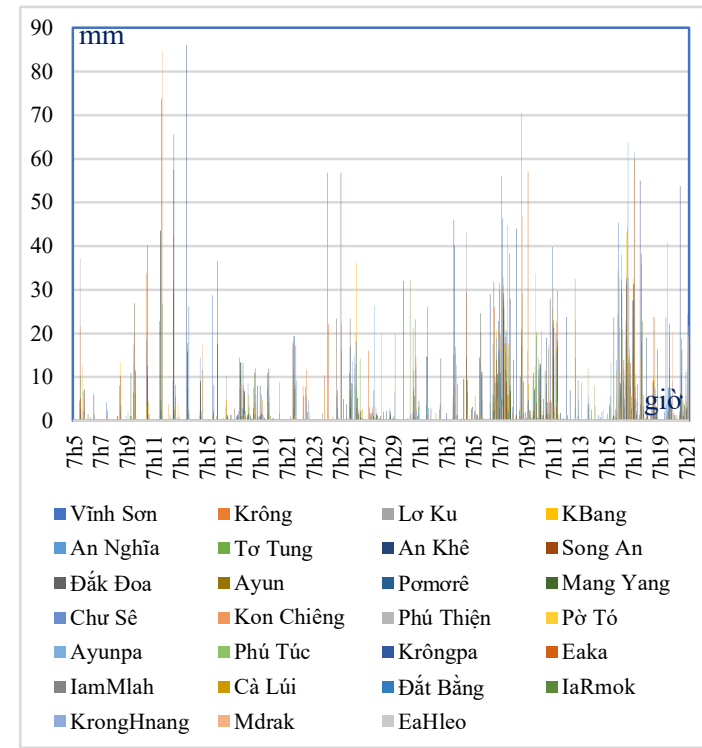

Hình 19. Lượng các trạm từ 1/9 đến 20/10 năm 2020. 


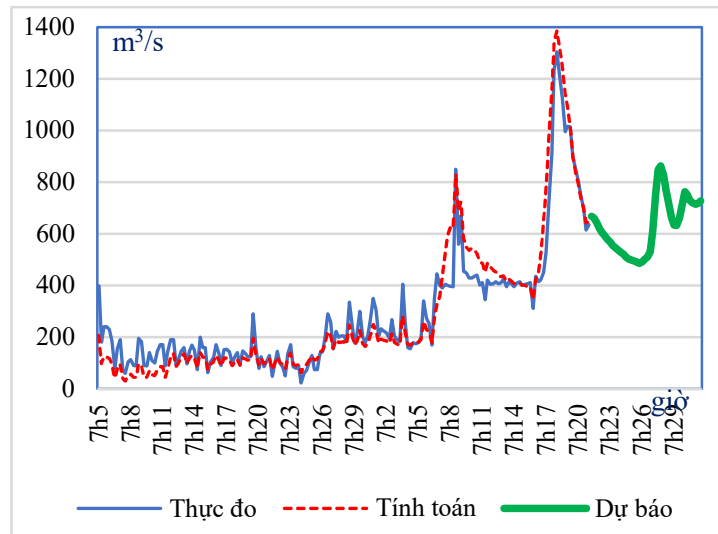

Hình 20. Dự báo lưu lượng thời hạn 5 ngày trạm Củng Sơn.

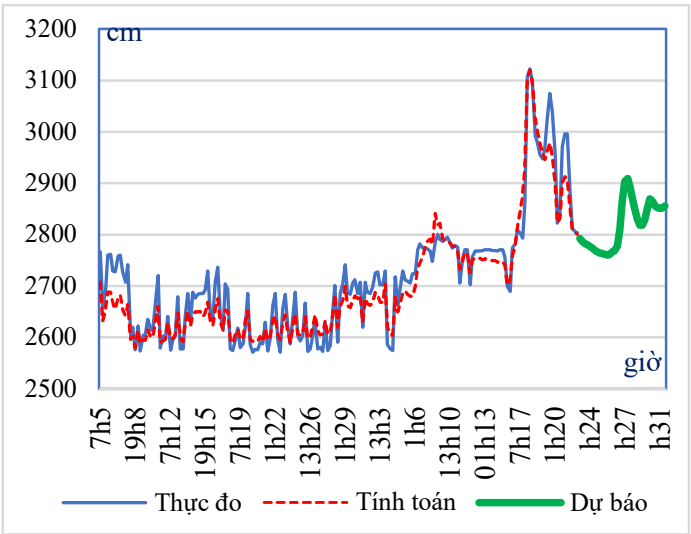

Hình 21. Dự báo mực nước thời hạn 5 ngày trạm Củng Sơn.

\section{Kết luận}

- Đánh giá chỉ tiêu Nash quá trình hiệu chỉnh bộ thông số mô hình Tank cho các hồ và trạm Củng Sơn từ 0,84 đến 0,86 , quá trỉnh kiểm định từ 0,80 đến 0,87 .

- Nghiên cứu đã hiệu chỉnh và kiểm định xác định được thông số nhám Manning của mô hình Sóng động học một chiều phi tuyến từ 0,031 đến 0,037 . Chất lượng hiệu chỉnh và kiểm định khá tốt, từ 0,84 đến 0,87 .

- Bộ thông số mô hình Tank và Sóng động học một chiều phi tuyến sau khi hiệu chỉnh, kiểm định đủ tin cậy để sử dụng dự báo thử nghiệm dòng chảy thời hạn vừa tại trạm thủy văn Củng Sơn. Đánh giá chất lượng dự báo thời hạn 5 , từ ngày $1 / 9$ đến ngày $20 / 10$ đạt $85 \%$, vượt chỉ tiêu của Tổng cục Khí tượng Thủy văn $10 \%$.

Đóng góp của tác giả: Xây dựng ý tưởng nghiên cứu: B.V.C., T.N.A.; Lựa chọn phương pháp nghiên cứu: B.V.C., T.N.A.; Xử lý số liệu: N.Q.H., N.T.H.; Thiết lập mô hình: B.V.C., N.T.H.; Ứng dụng thử nghiệm: N.Q.H., N.T.H.; Viết bản thảo bài báo: B.V.C., T.N.A.; Chỉnh sửa bài báo: B.V.C., T.N.A.

Lời cảm ơn: Nghiên cứu này được thực hiện dựa trên kết quả nghiên cứu LATS với đề tài "Nghiên cứu tích hợp bộ mô hình để khôi phục dòng chảy và dự báo thủy văn cho các sông thiếu số liệu quan trắc" và đề tài nghiên cứu khoa học cấp cơ sở "Xây dựng công cụ dự báo thủy văn hạn vừa, hạn dài khu vực Nam Trung Bộ".

Lời cam đoan: Tập thể tác giả cam đoan bài báo này là công trình nghiên cứu của tập thể tác giả, chưa được công bố ở đâu, không được sao chép từ những nghiên cứu trước đây; không có sự tranh chấp lợi ích trong nhóm tác giả.

\section{Tài liệu tham khảo}

1. Khải, N.H.; Sơn, N.T. Mô hình toán thủy văn. Nxb Đại học Quốc gia Hà Nội, 2003.

2. Jeffrey, E.M. Basic Concepts of Kinematic-Wave Models. U.S. Geological Survey Professional 1984, pp. 1302.

3. Mei, X.F.; Gelder, V.; Dai, Z.; Tang, Z.H. Impact of dams on flood occurrence of selected rivers in theUnited States. Front. Earth Sci. 2017, 11, 268-282. https://doi.org/10.1007/s11707-016-0592-1.

4. Hạnh, N.Đ.; Nhung, H.T.L. Úng dụng phương pháp Runge-Kutta diễn toán lũ qua hồ chứa Cửa Đạt trên sông Chu. Tạp chi Khoa học ĐHQGHN, Khoa học Tụ nhiên và Công nghệ 27 2011, 1S, 81-85. 
5. Thông tư số 06/2016/TT - BTNMT ngày 16 tháng 5 năm 2016 của Bộ Tài nguyên và Môi trường về Quy định loại bản tin và thời hạn dự báo cảnh báo khí tượng thủy văn, 2016.

6. Dũng, P.T. Báo cáo tổng kết đề tài nghiên cứu khoa học cấp Bộ: Nghiên cứu xây dựng công nghệ dự báo thủy văn hạn vừa hạn dài mùa cạn phục vụ Quy trình vận hành liên hồ chứa cho các sông chính ở khu vực Tây Nguyên. Bộ Tài nguyên và Môi trường, 2017.

7. Quyết định số $878 / \mathrm{Q} Đ-T T g$ ngày 18 tháng 7 năm 2018 của Thủ tướng Chính phủ về việc Ban hành Quy trình vận hành liên hồ chứa lưu vực sông Ba, 2018.

8. Techow, V.; Maidment; D.R.; Larry, W.M. Applied Hydrology, New York: McGraw - Hill, 1988.

9. Simons, D.B.; Li , R.M.; Stevens, M.A. Development of models for prediction water and sediment routing and yield from storms on small watershed. Colo State Univ. 1975, Rep CER74-75DBS-RML-MAS24.

10. Chanh, B.V.; Anh, T.N.; Anh, L.T. Mô phỏng dòng chảy trong sông bằng sóng động học một chiều phi tuyến. Tạp chí Đại học Quốc gia Hà Nội: Các Khoa học Trái đất và Môi truờng 2016, 32, 14-19.

11. Moriasi, D.N.; Arnold, J.G.; Liew, M.W. Model evaluation guidelines for systematic quantifcation of accuracy in watershed simulations. Am. Soc. Agric. Biol Eng. 2007, 50, 885-900.

12. https://earthexplorer.usgs.gov

13. Tảo, V.V.; Cẩm, N.C. Thủy lực. Nxb Nông nghiệp, 2006.

14. Thông tư số 42/2017/TT-BTNMT ngày 23 tháng 10 năm 2017 của Bộ Tài nguyên và Môi trường về việc Quy định kỹ thuật đánh giá chất lượng dự báo, cảnh báo thủy văn.

\section{Integrating experimenting of Tank model and one dimension Kinematic wave model for medium term hydrology forecasting on Ba river basin}

Bui Van Chanh ${ }^{1 *}$, Tran Ngoc Anh ${ }^{2,3}$, Nguyen Quoc Huan', Nguyen Thi Hoan"

${ }^{1}$ Southern Central Region Hydro-Meteorology Center, Vietnam Meteorological and Hydrological Administration; buivanchanh@gmail.com; huantvtp@gmail.com; hoannguyen.1311@gmail.com

${ }^{2}$ Center for Environmental Fluid Dynamic, VNU University of Science, Vietnam; tranngocanh@hus.edu.vn

${ }^{3}$ Faculty of Hydro-Meteorology and Oceanography, VNU University of Science, Vietnam

Abstract: Tank model is applied for long time and used commonly in the world which become usefull hydrology forecasting tool in many forecasting offices. However, Tank is a lump rainfall runoff model so it can't simulate flood moving and concentrating flow progess on basin which is restrain simulation. On small basin, Tank model is assessed using well result because flow concentrating and moving progress is little impaction to discharge progress at basin outlet. Besides, considerable impaction of reservoir to discharge of river which also can't simulate in Tank model so its simulation quality is reduce. For simulating by Tank model in big basin and simulating impact of reservoir to flow in river, this researching integrated Tank model with nonlinear Kinematic wave model and Runge Kutta level 3 method. The integration model is experimented using to forecast hydrology five-day term on Ba basin, its simulation and forecasting result are better than those of only use Tank model. The integration model is base to establish medium term hydrology forecasting project at Cung Son hydrology station in Central Southern Region HydroMeteorology Center.

Keywords: Tank model; Kinematic wave; Ba River basin. 